\title{
Competition at the feed bunk changes the feeding, standing, and social behavior of transition dairy cows
}

\author{
K. L. Proudfoot, ${ }^{*}$ D. M. Veira, $†$ D. M. Weary, ${ }^{*}$ and M. A. G. von Keyserlingk ${ }^{* 1}$ \\ ${ }^{*}$ Animal Welfare Program, Faculty of Land and Food Systems, University of British Columbia, 2357 Main Mall, Vancouver, British Columbia, \\ V6T 1Z4, Canada \\ †Agriculture and Agri-Food Canada, PO Box 1000, Agassiz, British Columbia, V0M 1A0, Canada
}

\section{ABSTRACT}

Transition dairy cows are vulnerable to the negative consequences of depressed feed intake around calving. Competition can decrease feeding activity in midlactation cows, but the effects of competition on the transition cow are not well understood. The objective was to test the effect of competition on the behavior and feed intake of transition cows. Standing behavior, feeding behavior, and dry matter intake were monitored from $1 \mathrm{wk}$ before to $2 \mathrm{wk}$ after calving for 36 Holstein dairy cows. Displacements at the feed bins were recorded the week before calving. Cows were assigned to either competitive (2:1 cows:feed bin) or noncompetitive (1:1 cow:feed bin) treatments. Treatment groups were balanced for parity and baseline feeding measures, resulting in 8 primiparous and 10 multiparous cows per treatment. Competition increased the number of displacements at the feed bins for both primiparous and multiparous cows. Primiparous cows had no change in feed intake or standing time when fed in a competitive environment, but did increase the time spent for each meal during the week before calving $(28 \pm 1.5$ vs. 24 $\pm 1.5 \mathrm{~min} / \mathrm{meal})$. In the week before and after calving, competitively fed multiparous cows had a lower feeding time per visit than noncompetitively fed cows $(4.2 \pm$ 0.5 vs. $5.8 \pm 0.5 \mathrm{~kg} /$ visit and $5.3 \pm 0.7$ vs. $7.0 \pm 0.7$ $\mathrm{kg}$ /visit, respectively). Multiparous cows ate at a faster rate 2 wk after calving $(142 \pm 11$ vs. $105 \pm 11 \mathrm{~g} /$ min). Multiparous cows in the competitive treatment increased the time they spent standing (without eating) during the week after calving compared with cows in the noncompetitive treatment $(820 \pm 44$ vs. $649 \pm 44$ $\mathrm{min} / \mathrm{d}$ ). Feeding rate was correlated with a displacement index in multiparous cows, whereby cows with lower displacement indices ate more rapidly. Results indicate that restricting access to feed increases dis-

Received September 15, 2008.

Accepted March 13, 2009.

${ }^{1}$ Corresponding author: nina@interchange.ubc.ca placements regardless of parity, and alters the feeding and standing behavior of primiparous and multiparous cows differently.

Key words: transition, competition, dry matter intake, behavior

\section{INTRODUCTION}

During the transition period, dairy cows are at high risk for infectious and metabolic diseases and lameness (Goff and Horst, 1997; Knott et al., 2007). Recent research has focused on risk factors for disease and lameness during transition. For example, DMI was identified as a contributor to disease susceptibility; cows that develop clinical and subclinical metritis after calving ate less than cows that remained healthy (Huzzey et al., 2007). The links between DMI and immunity are complex, and are likely driven by excessive negative energy balance during transition (Bell, 1995).

Although maintaining DMI during the transition period is important, little work has identified features of the environment that reduce the ability of the cow to consume feed during this period. Research on midlactation cows has identified management factors that affect feeding activity, such as design of the feed barrier and grouping strategy (DeVries et al., 2004; Huzzey et al., 2006). For instance, in free-stall housing systems where cows are given limited feeding space, competition at the feed bunk can reduce feeding activity. In turn, management strategies that reduced competition increased feeding activity, particularly for cows considered submissive at the feed bunk (DeVries et al., 2004). Competition at the feed bunk also increased standing time as cows waited by the feed bunk to gain access to feed (Olofsson, 1999; Huzzey et al., 2006), and excessive standing time was linked to lameness (Greenough and Vermunt, 1991; Singh et al., 1993).

No work to date has identified the effect of competition on transition dairy cow behavior. We predicted, based on previous research, that reduced feeding space would increase competition and reduce feed intake, as well as alter the feeding and standing behavior of 
Table 1. Composition of feed for pre- and postpartum diets for primiparous and multiparous Holstein dairy cows fed competitively and noncompetitively during wk -1 before calving and after calving

\begin{tabular}{lcc}
\hline Ingredient (\%) & Prepartum & Postpartum \\
\hline Corn silage & 21.3 & 14.7 \\
Grass silage & - & 21.3 \\
Alfalfa hay & 42.8 & 12.3 \\
Concentrate mix & 35.9 & 51.7 \\
DM & 42.4 & 41.7 \\
CP & 16.0 & 17.4 \\
ADF & 26.1 & 19.2 \\
NDF & 36.4 & 31.1 \\
\hline
\end{tabular}

transition dairy cows. We expected individual cows to respond to competition differently. Previous work on transition cows has identified differences in nutrient requirements and feeding behavior between primiparous cows entering their first lactation and multiparous animals (NRC, 2001; Wathes et al., 2007). The aim was to test the effect of a competitive feeding environment for primiparous and multiparous cows separately.

\section{MATERIALS AND METHODS}

\section{Animals, Housing, and Diet}

Thirty-four primiparous and 76 multiparous (parity $=2.8 \pm 0.2$, mean $\pm \mathrm{SD}$ ) Holstein cows housed in 5 experimental pens at the Dairy Education and Research Centre, University of British Columbia (Agassiz, British Columbia, Canada) were used. Animals were cared for according to the guidelines of the Canadian Council on Animal Care (1993). Cows were housed in 1 baseline pen, 1 of 2 prepartum pens, and 1 of 2 postpartum pens. Each experimental pen was equipped with 6 feed bins designed to monitor feeding behavior and intake electronically (Insentec, Marknesse, the Netherlands). The baseline pen housed 6 cows, and the prepartum and postpartum pens housed 9 cows per pen throughout the experimental period.

Cows were provided feed ad libitum, with fresh feed delivered twice daily at approximately 0800 and 1600 h. Representative samples of the pre- and postpartum TMR were taken 3 times weekly to determine weekly DM, and these weekly samples were pooled monthly for nutrient composition analysis. Samples were dried at $60^{\circ} \mathrm{C}$ for $48 \mathrm{~h}$ to determine DM. Monthly samples were analyzed (Cumberland Valley Analytical Services Inc., Maugansville, MD) to determine the average CP, ADF, and NDF content of the feed (Table 1).

Cows were on a 60 -d dry period regimen $(59.5 \pm 4.2$ d). In the first 5 wk dry, cows were fed a $66 \%$ grass silage, $33 \%$ corn silage with grass hay, rye grass straw, and mineral supplement diet. At approximately $3 \mathrm{wk}$ before calving, cows entered the experiment and were fed a prepartum TMR, and after calving were fed a postpartum TMR formulated for high-producing cows. Table 2 shows the ingredients in the concentrate mix used for the pre- and postpartum diets.

\section{Experimental Design, Treatments, and Cow Participation}

Cows entered a baseline pen $23 \mathrm{~d}$ before the expected calving date ( $23 \pm 4 \mathrm{~d}$ before the actual calving date). In the baseline pen, cows were given exclusive access to 1 bin for approximately $5 \mathrm{~d}$. Data from d 3 and 4 of the baseline period were used to establish baseline feeding measures for each cow. At $18 \mathrm{~d}$ before expected calving $(18 \pm 4 \mathrm{~d}$ before the actual calving date), cows were moved to 1 of 2 prepartum pens, where they remained until calving. At signs of imminent calving (i.e., ud-

Table 2. Composition of concentrate mix fed in pre- and postpartum diets for primiparous and multiparous Holstein dairy cows fed competitively and noncompetitively during wk -1 before calving and after calving

\begin{tabular}{|c|c|c|}
\hline \multirow[b]{2}{*}{ Ingredient (\%) } & \multicolumn{2}{|c|}{ Supplement } \\
\hline & Prepartum & Postpartum \\
\hline Ground beet pulp & 60.64 & - \\
\hline Barley, rolled & 6.00 & 46.24 \\
\hline Soybean meal ${ }^{1}(48 \% \mathrm{CP})$ & - & 11.00 \\
\hline Wheat distiller grains & 10.00 & - \\
\hline Canola meal ${ }^{1}(37 \% \mathrm{CP})$ & 8.00 & 5.76 \\
\hline Corn, steam flaked ${ }^{2}$ & - & 8.00 \\
\hline Aminoplus $^{3}$ & 7.00 & 10.00 \\
\hline Mill run & - & 5.00 \\
\hline Corn distillers grains & - & 4.00 \\
\hline Vitamin E premix & 1.33 & - \\
\hline Corn gluten meal & - & 2.40 \\
\hline Farm-pak ${ }^{4}$ & 1.60 & - \\
\hline Megalac $^{5}$ & - & 1.20 \\
\hline Niacin premix & 0.88 & - \\
\hline Dicalcium phosphate & 1.00 & - \\
\hline Magnesium oxide & 0.76 & 0.24 \\
\hline Iodized salt & 0.60 & 0.60 \\
\hline Limestone & 0.59 & 2.62 \\
\hline Calcium sulfate & 0.50 & - \\
\hline Molasses & 0.40 & 1.50 \\
\hline Urea & - & 0.34 \\
\hline Vitamin-mineral premix & 0.27 & - \\
\hline Dairy premix $^{6}$ & 0.30 & 1.10 \\
\hline Selenium & 0.09 & - \\
\hline Vitamin A premix & 0.02 & - \\
\hline Sel-Plex $2000^{4}$ & 0.02 & - \\
\hline
\end{tabular}

${ }^{1}$ Solvent extracted.

${ }^{2}$ Density $=420$ to $480 \mathrm{~g} / \mathrm{L}$.

${ }^{3} \mathrm{Ag}$ Processing Inc., Omaha, NE.

${ }^{4}$ Alltech, Nicholasville, KY. Farm-pak includes a vitamin and mineral complex with active dry yeast $(60 \mathrm{~g} / \mathrm{d})$.

${ }^{5}$ Church and Dwight Co., Princeton, NJ.

${ }^{6}$ Akey, Lewisberg, OH. Dairy premix is a vitamin and mineral complex formulated for stage of lactation. 
der enlargement, milk let-down, relaxation of the tail ligament), cows were moved to an individual maternity pen. Within $24 \mathrm{~h}$ of calving, cows were moved into 1 of 2 postpartum pens, where they remained until 18 DIM.

Cows were assigned to treatment upon entry into the prepartum pen. Cows in the noncompetitive treatment $(\mathrm{n}=34)$ were trained to eat from a single feed bin; 2 cows were assigned to eat from a single feed bin in the competitive treatment $(\mathrm{n}=76)$. Cows in the competitive treatment were paired based on expected calving date so that any given pair could have included either or both primiparous and multiparous cows. After calving, cows in the competitive group were paired with the same cow as in the prepartum pen if they calved within $1 \mathrm{~d}$ of each other, or with a cow from another pair if the calving dates were separated by more than $1 \mathrm{~d}$.

We know of no previous work that looked specifically at the effects of competition at the feed bunk on transition cow behavior, yet between 0.61 and $0.76 \mathrm{~m}$ of linear feed bunk space per cow has been recommended for transition dairy cows (Shaver, 1993). The electronic feeding system used cannot be considered equivalent to traditional linear bunk space; however, as a comparison between the treatments used and other studies in the literature, the amount of feeding space in the competitive and noncompetitive treatments would be approximately 0.3 and $0.6 \mathrm{~m} /$ cow, respectively.

In the competitive treatment, data from the 2 cows in a pair cannot be considered independent. To generate only 1 experimental unit from each pair in the competitive treatment, only the first cow to calve was used for data analysis. Moreover, because behavior and intake were measured in the postpartum period as well as in the prepartum period, the postpartum pair of a cow was removed from the final data set if she had been re-paired after calving.

Thirty-nine cows with clinical health problems after calving were removed from the analysis (metritis: $\mathrm{n}=$ 16; mastitis: $\mathrm{n}=8$; retained placenta: $\mathrm{n}=6$; ketosis: $\mathrm{n}=4$; milk fever: $\mathrm{n}=4$; displaced abomasum: $\mathrm{n}=1$ ). After these cows were removed, 18 cows ( 8 primiparous and 10 multiparous) remained in the competitive treatment. These 18 cows were paired with 18 cows in the noncompetitive treatment on the basis of similarity in parity, BW, and DMI in the baseline period. Average gestation length was similar between treatment groups for primiparous and multiparous cows $(269.5 \pm 4.2 \mathrm{~d})$. Of the 18 competitively fed cows, 2 primiparous and 2 multiparous cows had the same partner before and after calving.

\section{Behavioral Data Collection}

Feeding behavior was measured using the Insentec feed intake system (Chapinal et al., 2007), which recorded the duration and amount of feed consumed during every visit to a feed bin. These measurements were used to calculate feeding rate per visit (i.e., the ratio of DMI per visit and feeding time per visit), daily feed intake, and daily feeding time.

To assess the effect of treatment on short-term feeding measurements, the literature reports both data collected during individual visits and the "meals" formed by grouping visits in time; the former was considered more sensitive to treatment because it was not a derived measurement (DeVries et al., 2003), and the latter was more biologically relevant (Tolkamp et al., 2000). Both the sensitive measurements collected during each visit to the feed bin and biologically relevant meals are reported.

A meal consisted of both the time a cow had her head in the feed bin and the intervals between feeding visits within a meal. The meal criterion was the minimum time interval away from the feed bins such that the next visit was considered a new meal, and was identified by discontinuities in the distribution of intervals by using the mixed distribution method described by Tolkamp and Kyriazakis (1999). Preliminary analyses revealed no differences between the parity groups or treatments in meal criteria, so pooled criteria of $16.7 \mathrm{~min}$ for the prepartum period and 20.1 min for the postpartum period were established and used to calculate the size and duration of meals, as well as the duration of time spent not feeding within a meal (i.e., within-meal interval).

To record standing behavior, each cow was fitted with a modified data logger (Gemini Dataloggers Ltd., Chichester, UK) previously validated to record daily standing time in dairy cows (O'Driscoll et al., 2008). A data logger was fixed to the hind leg of each experimental cow and recorded leg orientation (horizontal or vertical) at 1-min intervals. Data were collected from the logger once weekly at milking and used to calculate daily standing time and daily lying time. Daily idle standing time (i.e., the time cows spent standing without eating) was calculated as the difference between daily standing time and feeding time recorded from the feeding system.

Displacements at the feed bins were recorded using video images from 2 cameras (Panasonic WV-BP330, Panasonic, Osaka, Japan) mounted $6 \mathrm{~m}$ above the feed bins in each of the prepartum pens, a time-lapse videocassette recorder (Panasonic AG-6540), and a video multiplexer (Panasonic WJ-FS 216). Displacements were recorded during the $3 \mathrm{~h}$ after twice-daily delivery 
of fresh feed for $4 \mathrm{~d}$ (beginning at $\mathrm{d}-11 \pm 3$ ). A displacement was recorded when a butt or a push from the "actor" resulted in the complete withdrawal of the head of another cow (the "reactor") from the feed bin. Group composition in the pens was dynamic, so it was not possible to calculate a dominance rank within the group. Instead, an index of displacements was used, as described by Galindo and Broom (2000), which calculated the proportion of displacements a cow instigated relative to her overall displacements in the group.

\section{Statistical Analysis}

The cow was considered the experimental unit in all statistical tests. The UNIVARIATE procedure (version 9.1, SAS Institute, 2003) was used to screen the distributions of feeding time and DMI per visit, and the gestation length for normality and the presence of outliers. Of the 30,708 feeding events recorded by the feeding system, $850(2.8 \%)$ were identified as extreme outliers (i.e., more than 3 times outside the interquartile range) and were removed from the data set. No extreme outliers in gestation length were identified. Because of differences in actual and expected calving dates, complete feeding data were available only between -9 and +18 d relative to calving. Days $-1,0$, and +1 were removed before analysis because cows were moved to the maternity pen during this period. Day -2 prepartum was removed because of high between-cow variation in the recorded feeding variables. For all feeding and standing variables, data were summarized to create 1 observation per day per cow. The means of daily values were used to create weekly means for wk -1 (d -9 to -3$)$, $\mathrm{wk}+1(\mathrm{~d}+2$ to +8$)$, and $\mathrm{wk}+2(\mathrm{~d}+9$ to +18$)$. One value for displacements was obtained per cow from the mean of $4 \mathrm{~d}$ of observations.

Interactions were expected between parity (categorized as primiparous vs. multiparous) and treatment for most of the recorded behaviors, so differences between treatments were tested separately for primiparous and multiparous cows. The MIXED procedure in SAS was used to test the fixed effect of treatment on feeding, standing, and social behavior variables for each parity category and weekly period. Pen was included in the model as a random effect. Least squares means and standard errors were determined using the LSMEANS statement in the MIXED procedure.

Social behavior at the feed bins was expected to help account for between-cow differences in the response to competition. These relationships for cows fed in the noncompetitive environment were not expected because our displacement index for cows fed noncompetitively was much less meaningful (these cows had nothing to gain by displacing other cows because they had unrestricted access to their own feed bins). Regression analysis for cows in the competitive treatment (GLM procedure in SAS) was used to evaluate the relationship between the displacement index and feeding variables, with pen included in the model as a class effect.

Differences in milk production between treatments were evaluated for the periods postcalving (i.e., wk +1 and +2 ) using the same model described above for feeding behavior. For all tests, significant differences were considered as $P<0.05$.

\section{RESULTS}

\section{Milk Production}

There were no differences in milk production in competitive and noncompetitive treatments for primiparous (wk $+1: 25.0 \pm 1.5$ vs. $23.3 \pm 1.3, P=0.41$; wk +2 : $28.8 \pm 1.6$ vs. $27.1 \pm 1.5, P=0.43)$ or multiparous cows (wk $+1: 36.7 \pm 2.5$ vs. $38.7 \pm 2.2, P=0.55$; wk $+2: 40.5 \pm 2.1$ vs. $42.4 \pm 2.0, P=0.51)$.

\section{Social Behavior}

Competitively fed cows had a higher frequency of displacements from the feed bins in wk -1 compared with noncompetitively fed cows (Figure 1). Competitively fed primiparous cows were involved in more than 3 times more displacements per day than their noncompetitively fed counterparts ( 25 vs. $7 / \mathrm{d}, \pm \mathrm{SE}=2.2$; $P<0.001)$; multiparous cows fed competitively were involved in more than twice as many displacements per day as noncompetitively fed cows (24 vs. 10/d, \pm 3.8 , $P=0.02)$.

\section{Feeding Behavior}

Although competitively fed primiparous cows were involved in more displacements at the feed bins than the noncompetitive primiparous cows, competition did not affect the frequency of feed bin visits, time at the feed bins, amount consumed during each visit, and total daily feeding time for these cows (Table 3 ).

In multiparous cows, competition tended to increase the frequency of visits to the feed bins during wk -1 (Table 3). In the week before calving, competitively fed multiparous cows spent $28 \%$ less time eating than noncompetitively fed multiparous cows, resulting in a tendency for lower DMI per visit. In wk +1 , competition had no effect on the number of visits to the feed bins, but multiparous cows fed competitively continued to spend less time eating per visit. By the second week after calving, intake per visit did not differ, but feeding rate was higher for the competitively fed cows. 
Table 3. The effect of competition on non-meal-based feeding variables shown separately for primiparous and multiparous Holstein dairy cows for the week before calving to 2 wk after calving

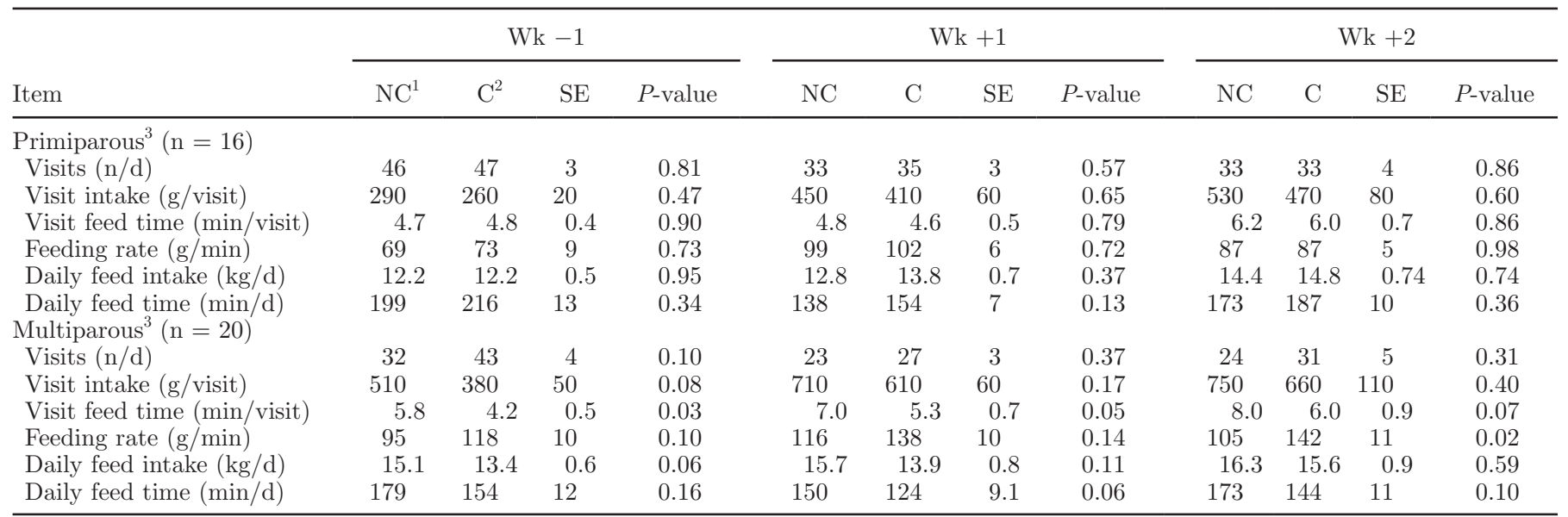

${ }^{1} \mathrm{NC}=$ noncompetitive treatment.

${ }^{2} \mathrm{C}=$ competitive treatment.

${ }^{3}$ Feed intake is reported on a DM basis as LSM \pm SE.

Before calving, primiparous cows fed competitively had longer meals than those fed noncompetitively; this increase was driven by longer intervals within meals (i.e., the time spent between feeding bouts within a single meal; Table 4). During wk +1 , meal duration tended to be longer in competitively fed primiparous cows compared with noncompetitively fed primiparous cows, but this effect was not present by wk +2 .

\section{Standing Behavior}

Competition did not affect time spent standing by primiparous cows (Figure 2), but it did for multiparous cows. Competitively fed multiparous cows tended to spend more time standing without eating during wk -1 . By wk +1 , competitively fed multiparous cows spent $2.8 \mathrm{~h}$ more time standing without eating than their

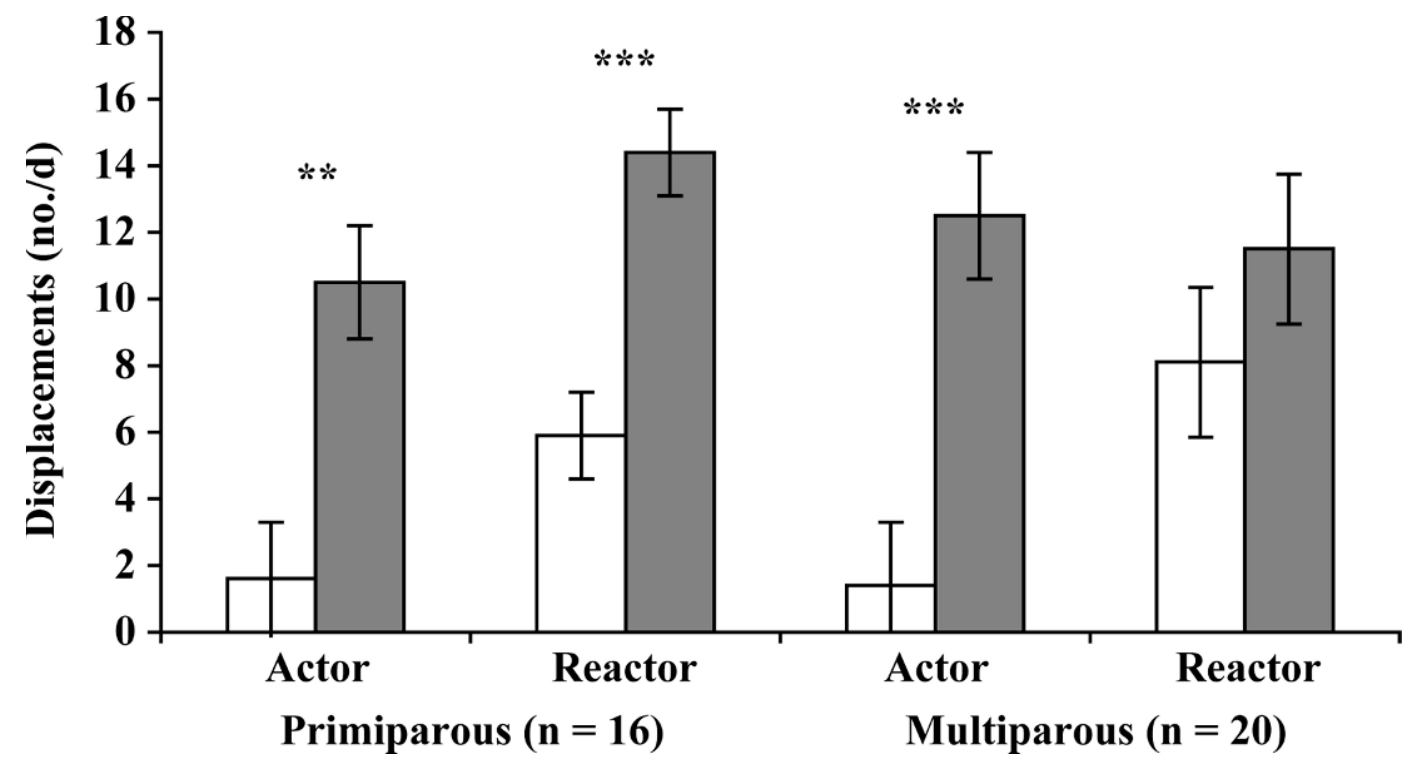

Figure 1. The effect of competition on displacements at the feed bins for primiparous and multiparous Holstein dairy cows fed competitively (gray bars) and noncompetitively (white bars) during wk -1 before calving (LSM \pm SE). Actor = displaced the reactor cow at the feed bin; reactor $=$ was displaced at the feed bin by the actor. For every displacement recorded at the feed bins, there was 1 actor and 1 reactor; therefore, if all animals in the experiment were included in the analysis, there would be a 1:1 (actor:reactor) ratio. The imbalance was expected because noncompetitive cows rarely instigated a displacement, and at any given time in the experiment, the number of competitive cows outnumbered the noncompetitive cows 6:3 in each pen. However, in the final analyses, only 1 cow from each matched pair was used, thus creating an imbalanced actor:reactor ratio. ${ }^{* *} P<0.01 ; * * P<0.001$. 
Table 4. The effect of competition on meal-based variables for primiparous and multiparous Holstein dairy cows from wk -1 before calving to wk +2 after calving

\begin{tabular}{|c|c|c|c|c|c|c|c|c|c|c|c|c|}
\hline Item & \multicolumn{4}{|c|}{$\mathrm{Wk}-1^{1}$} & \multicolumn{4}{|c|}{$\mathrm{Wk}+1^{2}$} & \multicolumn{4}{|c|}{$\mathrm{Wk}+2^{2}$} \\
\hline \multicolumn{13}{|l|}{$\operatorname{Primiparous}^{5}(\mathrm{n}=16)$} \\
\hline Meal frequency $(\mathrm{n} / \mathrm{d})$ & 11 & 11 & 0.7 & 0.33 & 10 & 9 & 0.5 & 0.80 & 9 & 9 & 0.5 & 0.82 \\
\hline Meal time (min/meal) & 24.0 & 28.0 & 1.5 & 0.04 & 19.8 & 24.4 & 1.7 & 0.07 & 25.1 & 28.6 & 1.9 & 0.21 \\
\hline Meal size (kg/meal) & 1.1 & 1.2 & 0.1 & 0.48 & 1.4 & 1.5 & 0.1 & 0.21 & 1.7 & 1.7 & 0.1 & 0.77 \\
\hline Within-meal time (min) & 6.0 & 7.8 & 0.8 & 0.05 & 5.1 & 7.1 & 0.9 & 0.12 & 5.3 & 7.2 & 0.8 & 0.13 \\
\hline Meal time (min/meal) & 25.2 & 25.8 & 2.2 & 0.85 & 20.6 & 18.7 & 1.1 & 0.24 & 25.9 & 24.8 & 1.9 & 0.70 \\
\hline Meal size (kg/meal) & 1.7 & 1.5 & 0.1 & 0.25 & 1.7 & 1.5 & 0.1 & 0.10 & 2.0 & 1.9 & 0.1 & 0.59 \\
\hline Within-meal time (min) & 6.1 & 8.9 & 1.1 & 0.11 & 3.9 & 5.2 & 0.5 & 0.11 & 4.6 & 7.1 & 1.0 & 0.10 \\
\hline
\end{tabular}

${ }^{1}$ Meal criterion was established as $16.7 \mathrm{~min}$ in wk -1 for both parity groups.

${ }^{2}$ Meal criterion was established as $20.1 \mathrm{~min}$ for wk +1 and $\mathrm{wk}+2$ for both parity groups.

${ }^{3} \mathrm{NC}=$ noncompetitive treatment

${ }^{4} \mathrm{C}=$ competitive treatment.

${ }^{5}$ Feed intake is reported on a DM basis as LSM $\pm \mathrm{SE}$.

noncompetitively fed counterparts. A greater standing time was accompanied by decreased lying time by the competitively fed multiparous cows (494 vs. $641 \pm 41$ $\min / \mathrm{d} ; P<0.01)$. On wk +2 , competitively fed mul-

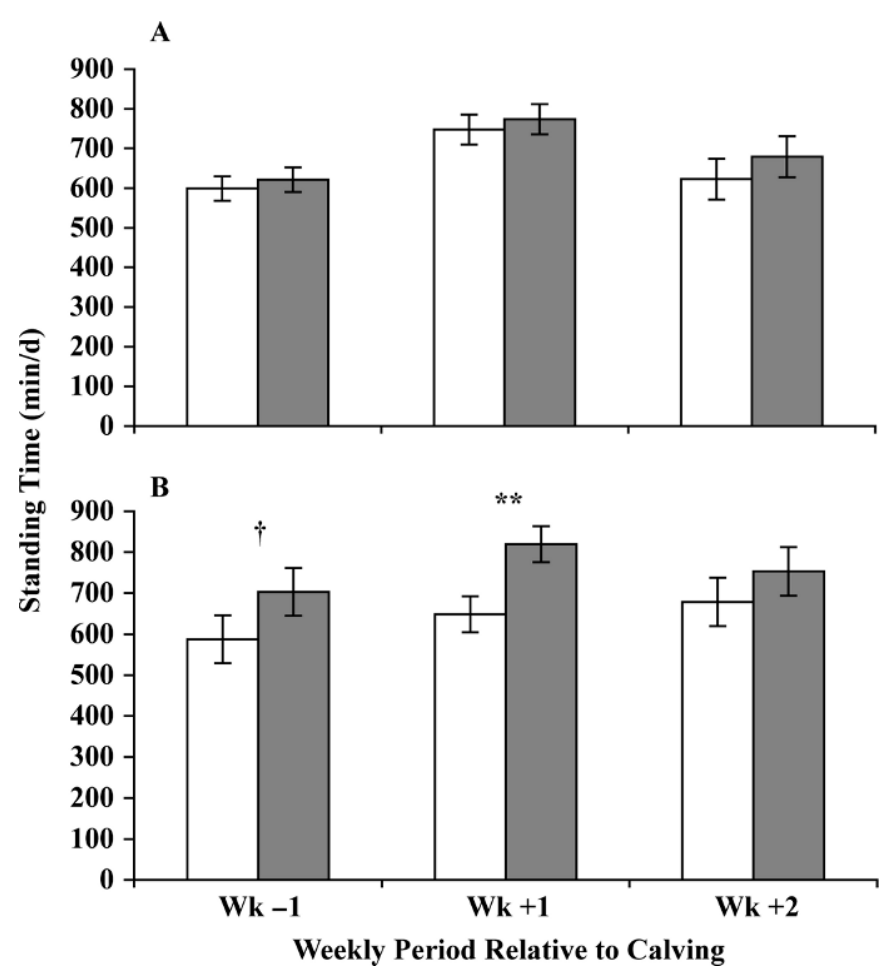

Figure 2. Standing time $(\mathrm{min} / \mathrm{d})$ of $\mathrm{A}$ ) primiparous and $\mathrm{B})$ multiparous Holstein dairy cows fed competitively (gray bars) and noncompetitively (white bars) from wk -1 to +2 relative to calving (LSM $\pm \mathrm{SE}) . \dagger P<0.10 ;{ }^{* *} P<0.01$. Standing time does not include the time cows spent feeding. tiparous cows did not differ from noncompetitively fed multiparous cows.

\section{Relationship Between the Displacement Index and Feeding Variables}

There was no relationship between the displacement index and daily DMI for multiparous or primiparous cows. However, there was a relationship between feeding rate and the displacement index $\left(\mathrm{R}^{2}=0.82 ; P\right.$ $<0.001$ ) in the competitively fed multiparous cows (Figure 3), whereby cows with the lowest displacement index (i.e., displaced their partner less often than they were displaced) ate the fastest.

\section{DISCUSSION}

The results confirmed that a competitive feeding environment increased displacements at the feed bins regardless of parity. Limiting access to feed bins or a feed bunk increased displacements from the feed bins in several studies (Olofsson, 1999; DeVries et al., 2004; Huzzey et al., 2006). The effect of competition on displacements among close-up dry cows was similar to that observed in midlactation cows overstocked at feed bins (4 cows:1 bin; Olofsson, 1999) or at a post-and-rail feeding barrier $(0.21 \mathrm{~m} /$ cow; Huzzey et al., 2006).

In midlactation cow studies, displacements were considered a driving force behind changes in feeding and standing behaviors, including increased feeding rate (Olofsson, 1999), decreased feeding time, and increased standing time (Huzzey et al., 2006). Because cows during transition are much more vulnerable to the negative consequences of changes in feeding and standing behav- 
ior, one aim was to determine how placement of a cow in the displacement index affected her response to a competitive feeding environment. In support of previous work with midlactation cows, multiparous cows during wk +2 adapted to increased competition at the feed bins by increasing their rate of feed intake at each visit to the feed bin (Harb et al., 1985; Olofsson, 1999). Factors affecting feeding rate have been discussed (Nielsen, 1999) and include increased motivation to feed and increased social pressure at the feeding area. Most (82\%) of the variation in feeding rate in the multiparous cows was explained by their displacement index; cows with lower indices ate more rapidly. The literature on social competition in animals distinguishes between indirect ("scramble") and direct ("interference") competition (Giraldeau and Caraco, 2000). Those cows less able to compete for feed using displacements (interference competition) were more likely to increase their feeding rate (scramble competition) when they were able to access the feed bins. In contrast, on pasture (where feeding resources are more abundant and spread out) dominant cows ate and chewed faster than subordinate cows (Phillips and Rind, 2002), perhaps because subordinate cows spent more time performing vigilance behaviors.

Few studies have tested the effect of competition on DMI. In recent work, DeVries et al. (2004) and Huzzey et al. (2006) found that decreasing stocking density increased feeding time, particularly in cows considered subordinate at the feed bunk. Olofsson (1999) found that competition slightly increased the DMI of dairy cows, and this increase was driven by an increase in feeding rate. The current study is the first to report that competition had a tendency to decrease the feed intake of multiparous dry cows in the week before calving. This decrease was driven by a tendency for smaller intakes during each feeding visit and not by changes in meals. After calving, competition did not affect intake, perhaps because all cows were highly motivated to increase intakes to meet the energy requirements of lactation. Because recent research (Huzzey et al. 2007) has identified minor decreases in DMI before calving as a risk factor for disease postcalving, further work is needed to assess the effect of competition on immunity and disease incidence after calving.

Competition increased the standing time of multiparous cows in the week after calving. Previous work showed that competition at the feed bunk increased standing time in midlactation cows (Olofsson, 1999; Huzzey et al., 2006). The multiparous cows decreased their daily lying time in the week after calving in response to competition; the remainder of the day was spent standing. Where the standing occurred (i.e., alley or stall) was not recorded, but previous work suggests

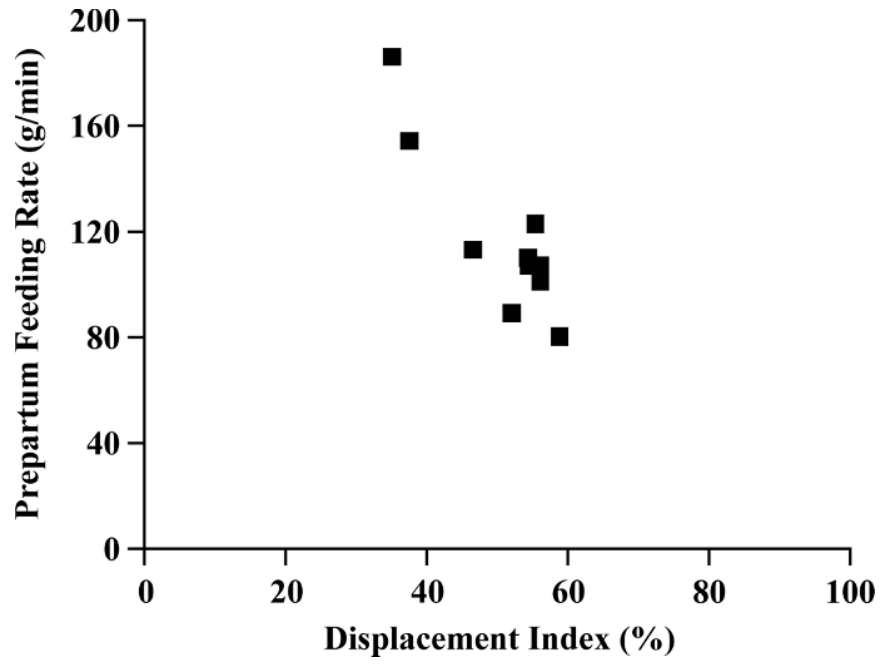

Figure 3. The relationship between feeding rate and displacement index for competitively fed multiparous Holstein dairy cows $(\mathrm{n}=10)$ during wk -1 before calving. The displacement index was calculated as the ratio of actor instigations to the total number of recorded displacements for each cow.

that these cows were likely standing in the feeding area, waiting to gain access to the feed bunk (Galindo and Broom, 2000; Huzzey et al., 2006). The increased effect of competition on standing time during the week after calving may have been due to the introduction of a new social partner at calving.

Excessive standing time is a risk factor for developing lameness conditions such as claw horn lesions (Greenough and Vermunt, 1991; Singh et al., 1993). Avoiding excessive standing is important throughout lactation, but the period around calving may be critical for the development of hoof pathologies. For instance, claw horn lesions, which are delayed clinical signs of horn disruption by approximately 8 to $12 \mathrm{wk}$, were most commonly identified in the few months after calving (Knott et al., 2007).

\section{CONCLUSIONS}

In this study, competition at feed bins increased the number of displacements at the feed bunk for both primiparous and multiparous cows. There was a tendency for multiparous cows fed competitively to eat less in the week before calving compared with cows fed noncompetitively. This reduction was driven by a tendency for lower intake during each feeding visit, rather than by consuming fewer meals. Competition increased the rate of intake of multiparous cows, particularly $2 \mathrm{wk}$ after calving; cows with the lowest displacement index ate the most rapidly. Additionally, multiparous cows fed competitively increased the time they spent stand- 
ing in the week after calving. The results of this study indicate that competition at the feeder can alter the behavior of dairy cows around the transition period, potentially increasing the risk of lameness and disease.

\section{ACKNOWLEDGMENTS}

We would like to thank the staff of The University of British Columbia Dairy Education and Research Centre and the University's Animal Welfare Program. In particular, we thank Lizanne Steunenberg for her contributions to daily data collection, Katie Neufeld for her help in analyzing the video recordings of social behavior, and Trevor DeVries for his comments on the statistical analyses. This project was funded by the Natural Sciences and Engineering Research Council of Canada and Dairy Farmers of Canada and many other donors listed on the Animal Welfare Web site at http:// www.landfood.ubc.ca/animalwelfare.

\section{REFERENCES}

Bell, A. W. 1995. Regulation of organic nutrient metabolism during transition from late pregnancy to early lactation. J. Anim. Sci. 73:2804-2819.

Canadian Council on Animal Care. 1993. Guide to the Care and Use of Experimental Animals. Vol. 1. E. D. Olfert, B. M. Cross, and A. A. McWilliam, ed. Can. Counc. Anim. Care, Ottawa, Ontario, Canada.

Chapinal, N., D. M. Veira, D. M. Weary, and M. A. G. von Keyserlingk. 2007. Validation of a system for monitoring individual feeding and drinking behavior and intake in group housed cattle. J. Dairy Sci. 90:5732-5736

DeVries, T. J., M. A. G. von Keyserlingk, and D. M. Weary. 2004. Effect of feeding space on the inter-cow distance, aggression, and feeding behavior of free-stall housed lactating dairy cows. J. Dairy Sci. 87:1432-1438.

DeVries, T. J., M. A. G. von Keyserlingk, D. M. Weary, and K. A. Beauchemin. 2003. Measuring the feeding behavior of lactating dairy cows in early to peak lactation. J. Dairy Sci. 86:33543361.

Galindo, F., and D. M. Broom. 2000. The relationships between social behavior of dairy cows and the occurrence of lameness in three herds. Res. Vet. Sci. 69:75-79.

Giraldeau, L. A., and T. Caraco. 2000. Social Foraging Theory. Princeton University Press, Princeton, N..
Goff, J. P., and R. L. Horst. 1997. Physiological changes at parturition and their relationships to metabolic disorders. J. Dairy Sci. 80:1260-1268.

Greenough, P. R., and J. J. Vermunt. 1991. Evaluation of subclinical laminitis in a dairy herd and observations on associated nutritional and management factors. Vet. Rec. 128:11-17.

Harb, M. Y., V. S. Reynolds, and R. C. Campling. 1985. Eating behavior, social dominance and voluntary intake of silage in groupfed milking cattle. Grass Forage Sci. 40:113-118.

Huzzey, J. M., T. J. DeVries, P. Valois, and M. A. G. von Keyserlingk. 2006. Stocking density and feed barrier design affect the feeding and social behavior of dairy cattle. J. Dairy Sci. 89:126-133.

Huzzey, J. M., D. M. Veira, D. M. Weary, and M. A. G. von Keyserlingk. 2007. Prepartum behavior and dry matter intake identify dairy cows at risk for metritis. J. Dairy Sci. 90:3220-3233.

Knott, L., J. F. Tarlton, H. Craft, and A. J. F. Webster. 2007. Effects of housing, parturition and diet change on the biochemistry and biomechanics of the support structures of the hoof of dairy heifers. Vet. J. 174:277-287.

Nielsen, B. L. 1999. On the interpretation of feeding behavior measures and the use of feeding rate as an indicator of social constraint. Appl. Anim. Behav. Sci. 63:79-91.

NRC. 2001. Nutrient Requirements of Dairy Cattle. 7th rev. ed. National Academy Press, Washington, DC.

O'Driscoll, K. O., L. Boyle, and A. Hanlon. 2008. A brief note on the validation of a system for recording lying behaviour in dairy cows Appl. Anim. Behav. Sci. 111:195-200.

Olofsson, J. 1999. Competition for total mixed diets fed for ad libitum intake using one or four cows per feeding station. J. Dairy Sci. 82:69-79

Phillips, C. J., and M. I. Rind. 2002. The effects of social dominance on the production and behavior of grazing dairy cows offered forage supplements. J. Dairy Sci. 85:51-59.

SAS Institute. 2003. SAS User's Guide. Version 9.1. SAS Inst. Inc. Cary, NC.

Shaver, R. D. 1993. TMR strategies for transition feeding of dairy cows. Pages 163-183 in J. Linn, G. Wagner, and P. DeSteno, ed. 54th Minnesota Nutr. Conf. and Natl. Renderers Technol. Symp. Bloomington, MN. Minnesota Coop. Ext. Serv., St. Paul.

Singh, S. S., W. R. Ward, K. Lautenbach, and R. D. Murray. 1993 Behavior of lame and normal dairy cows in cubicles and in a straw yard. Vet. Rec. 133:204-208

Tolkamp, B. J., and I. Kyriazakis. 1999. To split behavior into bouts, log-transform the intervals. Anim. Behav. 57:807-817.

Tolkamp, B. J., D. P. Schweitzer, and I. Kyriazakis. 2000. The biologically relevant unit for the analysis of short-term feeding behavior of dairy cows. J. Dairy Sci. 83:2057-2068.

Wathes, D. C., Z. Cheng, N. Bourne, V. J. Taylor, M. P. Coffey, and S. Brotherstone. 2007. Differences between primiparous and multiparous dairy cows in the inter-relationships between metabolic traits, milk yield and body condition score in the periparturient period. Domest. Anim. Endocrinol. 33:203-225. 